2017-07

\title{
Tracking reveals limited interactions between Campbell Albatross and fisheries during the breeding season
}

\author{
Sztukowski, LA
}

http://hdl.handle.net/10026.1/13440

\subsection{7/s10336-016-1425-4}

Journal of Ornithology

Springer Science and Business Media LLC

All content in PEARL is protected by copyright law. Author manuscripts are made available in accordance with publisher policies. Please cite only the published version using the details provided on the item record or document. In the absence of an open licence (e.g. Creative Commons), permissions for further reuse of content should be sought from the publisher or author. 


\section{TRACKING REVEALS LIMITED INTERACTIONS}

\section{BETWEEN CAMPBELL ALBATROSS AND FISHERIES}

\section{DURING THE BREEDING SEASON}

4 Lisa A. Sztukowski ${ }^{1}$, Mariëlle L. van Toor ${ }^{2}$, Henri Weimerskirch $^{3}$, David R. Thompson ${ }^{4}$,

5 Leigh G. Torres ${ }^{5}$, Paul M. Sagar ${ }^{6}$, Peter A. Cotton ${ }^{1}$, Stephen C. Votier ${ }^{7}$

$6{ }^{1}$ Marine Biology \& Ecology Research Centre, Plymouth University, Plymouth PL4 8AA,

$7 \quad$ UK

$8{ }^{2}$ Max Planck Institute for Ornithology, Department of Migration and Immuno-Exology,

9 Radolfzell, Germany

$10{ }^{3}$ Centre d'Etudes Biologiques de Chizé, CNRS, France

$11{ }^{4}$ National Institute of Water and Atmospheric Research Ltd. (NIWA), Wellington, New

12 Zealand

$13{ }^{5}$ Department of Fisheries and Wildlife, Marine Mammal Institute, Oregon State University,

14 Newport, Oregon, USA

$15{ }^{6}$ National Institute of Water and Atmospheric Research Ltd. (NIWA), Christchurch, New

16 Zealand

$17{ }^{7}$ Environment and Sustainability Institute, University of Exeter, Cornwall Campus, Penryn,

18 Cornwall TR10 9EZ, UK 


\section{Abstract}

21 The last century has seen a significant decline in global seabird populations that can, in part, be attributed to fisheries mortality. Understanding overlap between seabird distribution and fisheries is one important element in assessing the risk of bycatch, and may be achieved by tracking the movements of individual birds and fishing vessels. Here we assess the spatiotemporal overlap between the vulnerable Campbell Albatross Thalassarche impavida and large (>28m) commercial fishing boats in New Zealand's Exclusive Economic Zone (EEZ).

We used bivariate Gaussian bridge movement models to compute spatio-temporal utilization distributions, both from high-resolution bird-borne GPS loggers and the Vessel Monitoring System, to estimate potential interactions with fisheries during the breeding season. During incubation and chick brooding, $49.7 \%$ of the 28,814.9 hours Campbell Albatrosses spent foraging were within New Zealand's EEZ, utilizing $6.7 \%$ of the available area. Within the EEZ, albatrosses only overlapped with fisheries vessels in a relatively small section in the southern portion of these waters. Despite this spatial overlap, there was no evidence that albatrosses and fishing vessels were in the same location simultaneously. When accounting for the broader ecological footprint of fishing vessels, which can influence bird behaviour for up to $30 \mathrm{~km}$, we found albatross-vessel overlap in $8.4 \%$ of foraging trips. Overall, the low levels of spatial overlap could be a result of preference for foraging in areas without fishing activity or competitive exclusion by other species. While higher resolution data from both birds and vessels will improve our ability to detect the true nature of interactions, as opposed to just overlap, the current threat of bycatch during the breeding season appears comparatively low. Our results reinforce the importance of a multi-scale approach to risk assessment, as results that rely solely on large-scale spatial overlap may overestimate risk associated with fisheries. However, as Campbell Albatross spend approximately half of their 
44 time foraging outside New Zealand's EEZ, conservation and fisheries management for this species requires a multi-national focus.

46 Key words: seabird-fishery interactions, Campbell Albatross, New Zealand EEZ, bivariate

47 Gaussian Bridge movement models, spatio-temporal overlaps, bycatch

\section{Introduction}

49 Population declines in seabirds, particularly albatrosses and petrels, have been attributed to

50 fisheries-related mortality from accidental bycatch (Brothers 1991; Nel et al. 2002; Sullivan

51 et al. 2006; Rolland et al. 2010; Anderson et al. 2011). Globally, it is estimated that tens of

52 thousands of seabirds are killed every year - levels of mortality which are unsustainable.

53 However estimates of fisheries-related mortality vary greatly by location and among species

54 (Lewison and Crowder 2003; Anderson et al. 2011), and risk of bycatch is known to vary

55 within species as a function of sex, age, and inter-individual differences in foraging site

56 preference and behaviour (Nel et al. 2002; Votier et al. 2010; Tuck et al. 2015).

57 Conservation efforts to reduce seabird bycatch have been aided by identifying regions of

58 seabird-fishery overlap to inform mitigation measures. Recently, bird-borne tracking has been

59 used in tandem with spatially explicit fisheries data to better quantify the nature and extent of

60 spatio-temporal overlap (Votier et al. 2010; Granadeiro et al. 2011; Torres et al. 2011; Catry

61 et al. 2013; Torres et al. 2013a; Votier et al. 2013; Bodey et al. 2014; Collet et al. 2015;

62 Patrick et al. 2015). Various scales of analysis have been applied to seabird-fisheries overlap

63 and have highlighted contrasting results, in some cases due to the resolution of the data as

64 well as our limited ability to distinguish between interactions and overlap events (e.g. (Torres

65 et al. 2013a). Thus, combining and contrasting multiple spatial and temporal scales may 
66 provide complementary information necessary to enhance our understanding of the true

67 nature of seabird- fishery interactions.

68 In the present study, we examine the spatial and temporal overlap between fisheries vessels

69 and the vulnerable Campbell Albatross Thalassarche impavida. Following a decline of $72 \%$

70 from 1966-1984 (Waugh et al. 1999), the population has been comparatively stable, with

71 some suggestion of a slight decrease (Sagar 2014). In common with other species of

72 albatross, the steep population decline coincided with increased fisheries effort in the

73 Southern Ocean and variation in abundance has been attributed to the development of long-

74 line and trawl fisheries within the foraging range of these birds (Waugh et al. 1999; Moore

75 2004; Sagar 2014). Campbell Albatross, and the closely related Black-browed Albatross $T$.

76 melanophris, were regularly drowned by trawl fisheries and caught by longline vessels

77 (Murray et al. 1993; Croxall and Gales 1998; Gales et al. 1998). Thus, our goal was to

78 estimate the degree of spatio-temporal overlap between fisheries and breeding Campbell

79 Albatross within New Zealand's Exclusive Economic Zone (EEZ), to provide an updated

80 understanding of bycatch risk in these waters and compare results at multiple spatio-temporal

81 resolutions.

82 We used two approaches to identify potential interactions between fisheries and Campbell

83 Albatross during the breeding season. First, we used a novel method, bivariate Gaussian

84 bridges (BGB), to estimate the space use of both birds and vessels during the complete time

85 of tracking. This allows us to calculate the area of the EEZ used by albatrosses and vessels, as

86 well as to estimate how often albatrosses and fisheries use the same area at multiple temporal

87 scales. These results can be aggregated over time, such as breeding stage or season, which

88 provides estimates similar to population-level or multi-species assessments of overlap

89 between fishing activity and species distribution (e.g. kernel density analysis by (Phillips et 
al. 2006). If overlap between albatrosses and vessels occurs at the same time, this technique produces results comparable to the fine-scale tracking data on Black-browed Albatross and fisheries in waters around the Falkland Islands (Granadeiro et al. 2011, Catry et al. 2013). However, instead of using straight-line interpolation (and its associated assumptions) with (Torres et al. 2011) or without (Granadeiro et al. 2011) spatial buffers, we modelled motion variance, both parallel and orthogonal, to depict movement and space use more accurately. Second, since recent work has shown that birds may change their behaviour in response to fishing vessels, even as far away as $30 \mathrm{~km}$ (Bodey et al. 2014, Collet et al. 2015), we investigated events during which albatrosses were in proximity to fishing vessels and explored differences in overlap as a function of the spatial scale over which fishing vessel occurrence may affect bird behaviour. These seabird-vessel overlaps may indicate potential interactions, as spacing between seabirds and vessels may fluctuate at shorter time periods than were recorded (e.g. $<10$ minutes). This is similar to the results estimated by buffering known locations by distance and/or time (i.e. (Votier et al. 2010; Patrick et al. 2015).

104 Whenever we identified such a potential interaction event, we investigated whether the 105 frequency of bird-boat interactions was explained by sex, stage of reproduction (incubation and chick-brooding), and between two years. Because albatrosses have shorter foraging trips

107 during chick brooding, and therefore spend more time in the EEZ (Sztukowski 2016), we expected that there would be more interactions with fisheries during this stage compared with

109 incubation. Furthermore, because female Campbell Albatrosses tend to use areas that are

110 closer to the New Zealand mainland than males (Sztukowski 2016), we hypothesise that

111 females are more likely to encounter fishing vessels within the EEZ. Therefore, by examining

112 albatross-fishery overlap as a function of variations in distance between birds and boats, we

113 may increase our understanding of the factors, such as breeding stage and sex, that impact 
114 interactions at various spatial scales, with concomitant implications for assessing risk of 115 bycatch.

\section{Methods}

\section{Albatross tracking}

118 We studied the endemic Campbell Albatross on Campbell Island, New Zealand (52 $32^{\prime} 24^{\prime \prime}$, $119169^{\circ} 8^{\prime} 42^{\prime \prime} \mathrm{E}$ ) during two breeding seasons (10 November 2011 to 29 December 2011, and 19

120 October 2012 to 27 December 2012; hereafter referred to as study years 2011 and 2012

121 respectively). To record movement behaviour, we attached modified GT-600 i-gotU GPS

122 loggers (Mobile Action Technology, New Taipei City, Taiwan) to the central back feathers of 123 incubating and chick brooding adults using Tesa@ tape. GPS loggers were modified by

124 removing the external plastic housing, and then sealed with heat shrink tubing (FiniShrink, 125 UK) to waterproof each unit. The loggers weighed $33 \mathrm{~g}$, approximately $1.1 \%$ of albatross 126 body mass, and were set to record location every 10 minutes. Birds were re-captured on the 127 nest following one or more complete foraging trips, as determined by nest attendance 128 surveys. During capture, a small aliquot ( 0.05 ml) of blood was taken from each individual 129 for molecular sexing (Avian Biotech, Truro, Cornwall) under permit from the New Zealand 130 Department of Conservation.

\section{Vessel monitoring system}

132 We acquired data on the distribution and movement of fishing vessels via ship-borne GPS

133 transponders provided by the New Zealand Ministry of Fisheries fishing vessel-monitoring

134 system (VMS). Data were obtained for the same temporal period and spatial extent as the bird 135 tracks (i.e., 10 November 2011 to 29 December 2011 and 19 October 2012 to 27 December 136 2012). These data covered all fishing vessels $>28 \mathrm{~m}$ in length operating within the New 137 Zealand EEZ. Additionally, smaller vessels fishing for Orange Roughy (Hoplostethus 
atlanticus) or New Zealand Scampi (Metanephrops challengeri) were also tracked. VMS transponders record vessel identification, speed, and location every 1 to 2 hours; gear type was not reported. Catch-effort data for our study period lacked the usual corresponding

141 information needed to combine datasets. Catch-effort data also have low accuracy of event

142 locations with unknown error (Torres et al. 2011), and thus were not used in our analyses.

143 VMS data for areas outside the New Zealand EEZ were not available. Our analyses are 144 therefore restricted to overlaps between albatrosses and VMS enabled vessels within the New 145 Zealand EEZ, representing $49.7 \%$ of the $28,814.9$ hours during which we logged Campbell 146 Albatrosses on foraging trips.

\section{Data Analysis}

148 Spatio-temporal overlap between foraging albatrosses and fishing vessels within the EEZ

149 We used bivariate Gaussian bridge (BGB) movement models to calculate the temporally

150 explicit space use of both foraging Campbell Albatrosses and fisheries vessels to examine

151 their encounter probabilities. The advantage of BGBs over classic measures of utilization

152 distributions, such as convex polygons, or kernel home range, is that they track movement heterogeneity across time and use two directional components instead of one to gain more

154 precise estimates of the space utilized by individual animals/vessels. Moreover, space use

155 between any two locations can be computed separately, allowing for temporally explicit

156 estimates of the utilization distribution (Kranstauber et al. 2014). This allowed us to calculate

157 the spatial overlap between foraging albatrosses and fishing vessels contemporarily, and in

158 contrast to previous studies examining the interaction between seabirds and fisheries (e.g.

159 Granadeiro et al. 2011; Torres et al. 2011), we can determine space use directly from the

160 movement rather than relying on linear interpolation with or without a buffer zone. The use

161 of BGBs should thus provide more accurate results of spatio-temporal overlap. 
162 To prepare the tracking data, we split the VMS data into separate fishing trips with the same

163 format as the albatross data; each fishing vessel trip was defined as a series of GPS fixes that

164 were separated by a maximum of 24 hours. To prevent computational issues with birds and

165 fishing vessels crossing the international dateline we shifted the dateline of the data by 180

166 degrees prior to all analyses.

167 Coarse-scale spatio-temporal overlap between albatross and fisheries

168 First, we calculated the total area utilized by each individual albatross and vessel to estimate

169 the total spatial overlap during the complete study period (10 November 2011 to 29

170 December 2011, and 19 October 2012 to 27 December 2012). This coarse-scale spatio-

171 temporal index is similar to population-level or multi-species assessments of overlap between

172 fishing activity and species distribution (e.g. Phillips et al. 2006). We calculated the total

173 space use of birds and fishing vessels during each foraging/fishing trip by computing BGBs

174 on each complete trip, assuming a spatial location error of the GPS-devices of $18 \mathrm{~m}$ for both

175 the albatross data loggers and the VMS units of the vessels (Duncan et al. 2013). From these,

176 we extracted the $95 \%$ estimates of total space use with a spatial resolution of $5 \mathrm{~km}$, and re-

177 projected them to an equal-area projection. We then combined the space use estimates for all

178 bird foraging trips and fishing vessel trips separately, and calculated the coarse-scale spatial

179 overlap of these population-level space use estimates.

180 Fine-scale spatio-temporal overlap between albatross and fisheries

181 Secondly, we investigated whether birds and vessels shared similar areas during the same

182 time period, creating a potential for interactions. To do so, we split the BGB for each

183 albatross and vessel trip into its smallest temporal units: the space use between two

184 consecutive locations (i.e. every ten minutes for albatrosses, every 2 hours for vessels). From

185 these, we extracted the $95 \%$ utilization distributions with a spatial resolution of one square 
kilometre. For each potential encounter (utilization distributions with overlapping time intervals), we calculated the spatial overlap of the distribution estimates to estimate the area that was shared in space and time.

Distance between GPS-fix locations for albatross and fishing vessels: Sex, stage and year

190 effects

191 The assessment of spatio-temporal overlap using BGBs (above) estimates simultaneous space

192 use of foraging albatrosses and fishing vessels, however fisheries vessels can alter the

193 behaviour of foraging seabirds at greater spatial scales. It has been shown that Northern

194 Gannets (Morus bassanus) alter their behaviour as a response to the presence of fishing vessels within a range of up to $11 \mathrm{~km}$ (Bodey et al. 2014), and Wandering Albatross

196 (Diomedea exulans) up to a distance of $30 \mathrm{~km}$ (Collet et al. 2015). To encompass the full

197 effects of fishing vessels of foraging Campbell Albatross, we determined potential interaction events by calculating the distance to fishing vessels that were close in space and time using known locations. This is similar to modelling fishing vessel activity using windows of time and distance employed previously to avoid the assumptions associated with linear interpolation (i.e. Votier et al. 2010) or adding buffers to known locations (Patrick et al. 2015). First, we calculated the rhomb line distance from every GPS-fix of an albatross to every fishing vessel GPS-fix recorded within two hours (the temporal resolution of VMS tracks). Analyses used the full data set as well as the subset of the data where albatross and fishing vessel were $<11 \mathrm{~km}$ apart, assuming a conservative effect of the fishing vessel (Bodey et al. 2014); or <30 km apart (Collet et al. 2015). potential interactions, we modelled the minimum observed distances between albatross and any fishing vessel using linear mixed-effects models. The models included individual bird as 
210 a random effect (to control for repeat samples from the same bird) with year, sex and stage of

211 reproduction (incubation and chick brooding) as fixed-level factors. We also fitted the two-

212 way interaction between sex and stage of reproduction, to determine whether any sex-specific

213 effects of fisheries varied as a function of breeding stage.

\section{Results}

215 Over the two breeding seasons, we collected data from 299 foraging trips made by 81

216 Campbell Albatrosses (43 males and 38 females; Table 1). The total area used by albatross

217 within the EEZ was $291,128.2 \mathrm{~km}^{2}$ (6.7\% of the EEZ, representing $32.0 \%$ of the total area

218 used by birds). The rest of their foraging took place in the Tasman Sea, Australian waters or

219 in international waters (Fig. 1). For the fishing vessels (n=83), a total of 320,510 VMS fixes

220 were recorded during the same period of time, of which $99.9 \%$ were within the EEZ.

221 Subsequent results are thus based upon the EEZ only.

222 During their foraging trips, the albatrosses used a mean of 3,835.1 $\pm 5,930.2 \mathrm{~km}^{2}$ (mean \pm standard deviation; 95\% home range) and travelled over distances of 1,577.0 $\pm 2,222.5 \mathrm{~km}$ per trip (great-circle distances, see supplemental materials). Albatrosses spent 14,316.1 of the 28,814.9 hours within the EEZ (49.7\%).

\section{Coarse-scale spatio-temporal overlap between albatross and fisheries}

227 During the tracking period, we found that Campbell Albatrosses and vessels spatially

228 overlapped across $42,325.60 \mathrm{~km}^{2}$ within the EEZ when overlaying the full $95 \%$ utilization distributions (pooled data). Despite albatross using $6.7 \%$ of the EEZ, they overlapped with

230 fisheries vessels in just $0.97 \%$ of the EEZ, mostly in the south (Fig. 1). 


\section{Fine-scale spatio-temporal overlap between albatross and fisheries}

232 When calculating whether shared space use by albatrosses and fisheries occurred at the same

233 time, we used the temporally explicit $95 \%$ utilization distributions and found no overlap

234 between vessels and birds (Table 1). Overall, albatrosses used of 291,128.2 $\mathrm{km}^{2}$ within the

235 EEZ, and of this area, 42,325.6 $\mathrm{km}^{2}$ were also utilized by fishing vessels (supplemental

236 materials).

\section{Distance between GPS-fix locations for albatross and fishing vessels: Sex, stage} and year effects

The minimum distance between GPS-fix locations of albatrosses and fishing vessels on

240 foraging trips was significantly affected by breeding stage and year (Table 1). However, when using all spatial and temporal distances within $11 \mathrm{~km}$ and two hours of at least one vessel, albatrosses only overlapped during 17 of the 299 foraging trips (5.7\%; Table 2).

These 17 trips were performed by 15 individual birds that were within $11 \mathrm{~km}$ and two hours of a fishing vessel (range 1-8 vessels) at some stage during their foraging trip. Under this analysis, year was marginally significant in the subset of foraging trips as all but one of these foraging trips occurred in 2012. Fisheries overlap was most common during incubation and, while sex had no significant effect, 12 of the 17 foraging trips with fisheries overlap were by males, which may be due to sample size (Table 2). Under the scenario of a vessel footprint of $30 \mathrm{~km}$, albatross foraging behaviour was potentially affected by fishing vessels on 25 foraging trips $(8.4 \%)$ made by 21 individuals. Eighty percent of those foraging trips occurred during incubation with a sex ratio of 9:16 (female:male). The maximum number of vessels an individual potentially encountered increased from 8 within the $11 \mathrm{~km}$ footprint to 11 within the $30 \mathrm{~km}$ footprint. When testing the larger $(30 \mathrm{~km})$ footprint, sex, breeding stage and year were not significantly associated with the minimum distance between albatrosses and fishing 
256 less than $10 \%$ of the foraging trip within the EEZ (Table 2). However a few individuals spent 257 up to $65 \%$ of the foraging trip near vessels.

\section{Discussion}

259 We provide the first estimate of the degree of association between fisheries and breeding

260 Campbell Albatross using a novel BGB analysis at both coarse and fine spatio-temporal

261 scales. Despite Campbell Albatrosses utilizing 6.7\% of the New Zealand EEZ, they only

262 overlapped with fishing vessels in a remarkably small section in the southern portion of the

263 EEZ (0.97\% of the area). Furthermore, we found very limited spatio-temporal overlap

264 suggesting that albatrosses and vessels may occupy the same areas, but seldom at the same

265 time. These results suggest that during the breeding season the risk of fisheries bycatch for

266 Campbell Albatross is low within the New Zealand EEZ. In addition, this reveals that fishing

267 vessels are not always important as foraging opportunities for albatrosses. Below we discuss

268 the implications of these findings for studying seabird-fishery interactions in general and for the Campbell Albatross in particular.

Spatial area of overlap between albatross and vessels within the EEZ not only varied strongly

271 depending upon the spatio-temporal resolution used, the assumed vessel footprint, and

272 showed variation by sex and breeding stage. When accounting for an $11 \mathrm{~km}$ footprint (Bodey

273 et al. 2014), we found overlap in 5.7\% of trips, and these overlap periods generally lasted less than $10 \%$ of the trip within the EEZ. However a few individuals show substantial the spatiotemporal overlap and they may be at a higher risk of mortality. When we expanded this area to $30 \mathrm{~km}$, assuming that Campbell Albatrosses may behave like Wandering Albatrosses

277 (Collet et al. 2015), we found the potential for interactions increased to 8.4\% of foraging 278 trips. We expected females to have a higher risk of fisheries interactions based on time spent in proximity to the New Zealand mainland, where the highest fishing activities occur, but, 
contrary to our expectations, 12 of the 17 foraging trips within $11 \mathrm{~km}$ of fisheries vessels were by males. Further investigation is needed to determine if the skewed sex ratio is due to the small number of foraging trips with seabird-fisheries overlap or represent different survival probabilities as well as examining behavioural responses to assess if Campbell Albatross are attracted to vessels, avoid them, or co-occur/use the same habitat.

Campbell Albatross is a "High Risk" species within New Zealand waters, based upon a semiquantitative assessment of spatial overlap, observed captures, and fishing effort to assess fisheries vulnerability (Ministry for Primary Industries 2014). Prior to 1998, information on bycatch rates for Campbell Albatross was limited, as they were considered a subspecies of Black-browed Albatross (Robertson and Nunn 1998; Sangster et al. 2013); thus bycatch rates prior to 1998 were often a combination of Campbell and Black-browed Albatrosses. From 1989 to 1995, bycatch of Campbell Albatrosses in Australian waters was estimated at 780 per year (Gales et al. 1998), and thus could have had serious impacts on the estimated 24,600 annual breeding pairs in 1995-1998 (Moore 2004; Sagar 2014). Bycatch rates in this longline tuna fishery were higher (up to 1.26 birds per 1000 hooks) in summer than in winter, and skewed toward juveniles. Murray et al. (1993) reported declines in bycatch in New Zealand waters from 3662 seabirds in 1988 to 360 seabirds in 1992, suggesting mitigation measures may have reduced bycatch. Alternatively individuals that associated with fishing vessels could have been removed from the population, limiting the number of albatross around vessels (Tuck et al. 2015). More recently, there were zero to three observed captures of

300 Campbell Albatross per year from 2004 to 2013 (Abraham E. R., Thompson F. N). Thus, 301 current annual estimates of potential fatalities for Campbell Albatrosses within New Zealand waters range from 44 to 356 birds ((Ministry for Primary Industries 2014)); $0.20-1.69 \%$ of the estimated breeding population 2006-2012 (Sagar 2014). Most of the bycatch is associated with surface longline fisheries (Ministry for Primary Industries 2014). Observed captures 

(Abraham and Thompson 2012). If we assume that there are 21,648 individuals foraging at any one time, then over our study time period, we could expect up to 1803 albatross foraging trips to overlap with fishing vessels within New Zealand's EEZ (8.4\% of trips within $30 \mathrm{~km}$ footprint). Although it is unknown how many interactions with fishing vessels result in mortalities, these low bycatch rates agree well with the low overlap rates and lack of spatiotemporal overlap recorded in our tracking study. During the Austral summers of 2011/12 and 2012/13, Campbell Albatross spent about half their time foraging within the EEZ, however, the rest of their foraging took place in areas without available vessel monitoring data, mostly in the Tasman Sea or Australian waters. Thus, by focusing on VMS data within New Zealand's EEZ we probably underestimate the frequency of overlap between Campbell Albatross and fishing vessels, and our results are limited to the breeding season. Campbell Albatross may be vulnerable to fisheries related mortality in areas not studied here, and at different ages and breeding stages (Murray et al. 1993; Gales et al. 1998), but our tracking data is consistent with other sources of data indicating that bycatch risk of adult Campbell Albatross within the New Zealand EEZ is low during the breeding season.

There are a number of factors that may impact the nature of interactions between seabirds and fisheries, including the presence and timing of discards, the use of mitigation measures, weather, inter-species competition and the availability of other resources (Votier et al. 2008; Dietrich et al. 2008; Jiménez et al. 2009; Favero et al. 2011; Croxall et al. 2013). On the Patagonia Shelf, the frequency of Black-browed Albatross-fisheries interactions was associated with wind conditions, season, time of day, and the presence of discards (Favero et al. 2011). Management of discards, such as offal mincing, reducing discharge to sump water, 
or waste holding/batch discharge, can reduce the abundance of seabirds around fisheries vessels, with concomitant reductions in mortality risk (Abraham et al. 2009; Pierre et al. 2010). Additionally, mitigation measures, such as night setting, weighted lines and Tori lines, have reduced bycatch rates and may also deter seabird-fisheries interactions (Løkkeborg 2003; Dietrich et al. 2008). Inter-species competition may also reasonably account for the low interaction rates since fisheries within New Zealand's EEZ frequently kill other albatross species. White-capped Albatross (Thalassarche steadi), for example, regularly attend fishing vessels in New Zealand waters and may out-compete Campbell Albatross (Bartle 1991; Torres et al. 2011). Annual variation in these factors combined with environmental variation could account for annual influences found in our models; for example, the area utilized during foraging trips was larger during 2012.

\section{Conservation implications}

342 Our results suggest that, because of the limited overlap between Campbell Albatross and fisheries in New Zealand waters during the breeding season, the risk of bycatch is relatively low. Moreover, examining coarse-scale spatio-temporal overlap with fisheries may provide an overestimate of risk if not accounting for fine-scale temporal components that may be further reduced if behavioural state of the bird is added. These finer scale analyses of spatiotemporal overlap may both improve risk assessments and provide insight into foraging behaviour (Votier et al. 2010; Granadeiro et al. 2011; Croxall et al. 2013; Torres et al. 2013a; Torres et al. 2013b). While BGBs provide an excellent new tool to examine movements and overlaps between animals and fishing vessels, they require spatially and temporally explicit data. The regional focus of our study was constrained due to lack of data, thus reinforcing the need to increase the availability of high resolution fisheries data. Current estimates suggest that the population of Campbell Albatross is slightly declining or stable (Waugh et al. 1999; 
availability or environmental change should be carefully assessed. More importantly, conservation and fisheries management for this species needs to occur across all age-classes and on a multi-national scale, as juvenile Campbell Albatross may be more vulnerable to bycatch, and adult albatrosses spend half of their time foraging outside New Zealand waters. The timing and duration of mitigation measures could be improved by incorporating finescale spatio-temporal distributions into dynamic ocean management, in which management efforts to reduce bycatch change in response to spatial and temporal alteration in the ocean or species movements rather than largely static marine conservation areas (Howell et al. 2008; Hobday et al. 2010; Hobday et al. 2014).

\section{Acknowledgements}

We would like to thank the Campbell Island field crews, boat crews (particularly the RV Tiama), and Department of Conservation personnel, which made data collection possible. Special thanks to Caitlin Kroeger for field assistance, company and project discussions. Thanks also to Samantha Patrick, Nils Piechaud, Grant Humphries, Emilie Hall, Holly Armstrong, Clare Embling, Samantha Cox, and Andy Foggo for GIS assistance, thoughtful discussions and comments on drafts. We are grateful to New Zealand Ministry of Fisheries for providing access to the VMS data. This study was funded through a MARES Grant (FPA 2011-0016), National Institute of Water and Atmospheric Research Ltd. (NIWA), the New Zealand Department of Conservation and the New Zealand Ministry of Business, Innovation and Employment. Maps were created using ArcGIS® software (Ocean Basemap Sources: Esri, GEBCO, NOAA, National Geographic, De Lorme, HERE, Geonames.org, and other contributors) by Esri. ArcGIS ${ }^{\circledR}$ and ArcMap ${ }^{\mathrm{TM}}$ are the intellectual property of Esri and are used herein under license. 


\section{Compliance with ethical standards}

380 Conflict of interest The authors declare that they have no conflict of interest. All applicable

381 international, national, and/or institutional guidelines for the care and use of animals were

382 followed. All scientific procedures and site access were conducted under permit issued by the

383 New Zealand Department of Conservation and was approved by the animal ethics committee

384 at the Plymouth University. Great care was taken to minimize stress to the animals during

385 handling.

386

387

388

389

390

391

392

393

394

395

396

397

398

399

400

401

402

403

404

405

406

407

408

409

410

\section{References}

Abraham ER, Pierre JP, Middleton DA, et al (2009) Effectiveness of fish waste management strategies in reducing seabird attendance at a trawl vessel. Fish Res 95:210-219.

Abraham E. R., Thompson F. N Captures of birds in trawl fisheries, in the New Zealand Exclusive Economic Zone, during the 2010-11 fishing-year. Retrieved from http://data.dragonfly.co.nz/psc/v20121101/explore/, Apr 15, 2013. https://data.dragonfly.co.nz/psc/v20121101/explore/. Accessed 28 Jul 2015

Anderson O, Small C, Croxall J, et al (2011) Global seabird bycatch in longline fisheries. Endanger Species Res 14:91-106. doi: 10.3354/esr00347

Bartle JA (1991) Incidental capture of seabirds in the New Zealand subantarctic squid trawl fishery, 1990. Bird Conserv Int 1:351-359.

Bodey TW, Jessopp MJ, Votier SC, et al (2014) Seabird movement reveals the ecological footprint of fishing vessels. Curr Biol 24:R514-R515.

Brothers N (1991) Albatross mortality and associated bait loss in the Japanese longline fishery in the Southern Ocean. Biol Conserv 55:255-268.

Catry P, Lemos RT, Brickle P, et al (2013) Predicting the distribution of a threatened albatross: The importance of competition, fisheries and annual variability. Prog Oceanogr 110:1-10.

Collet J, Patrick SC, Weimerskirch H (2015) Albatrosses redirect flight towards vessels at the limit of their visual range. Mar Ecol Prog Ser 526:199-205.

Croxall J, Small C, Sullivan B, et al (2013) Appropriate scales and data to manage seabirdfishery interactions: Comment on Torres et al.(2013). Mar Ecol Prog Ser 493:297300.

Croxall JP, Gales R (1998) An assessment of the conservation status of albatrosses. Albatross Biol Conserv 46-65. 
Dietrich KS, Melvin EF, Conquest L (2008) Integrated weight longlines with paired streamer lines - Best practice to prevent seabird bycatch in demersal longline fisheries. Biol Conserv 141:1793-1805. doi: 10.1016/j.biocon.2008.04.023

Favero M, Blanco G, García G, et al (2011) Seabird mortality associated with ice trawlers in the Patagonian shelf: Effect of discards on the occurrence of interactions with fishing gear. Anim Conserv 14:131-139. doi: 10.1111/j.1469-1795.2010.00405.x

Gales R, Brothers N, Reid T (1998) Seabird mortality in the Japanese tuna longline fishery around Australia, 1988-1995. Biol Conserv 86:37-56.

Granadeiro JP, Phillips RA, Brickle P, Catry P (2011) Albatrosses following fishing vessels: How badly hooked are they on an easy meal? PLoS ONE 6:e17467. doi: 10.1371/journal.pone.0017467

Hobday AJ, Hartog JR, Timmiss T, Fielding J (2010) Dynamic spatial zoning to manage Southern Bluefin Tuna (Thunnus maccoyii) capture in a multi-species longline fishery. Fish Oceanogr 19:243-253.

Hobday AJ, Maxwell SM, Forgie J, et al (2014) Dynamic ocean management: Integrating scientific and technological capacity with law, policy and management. Stanf Environ Law J 33:125-165.

Howell EA, Kobayashi DR, Parker DM, et al (2008) TurtleWatch: A tool to aid in the bycatch reduction of Loggerhead Turtles Caretta caretta in the Hawaii-based pelagic longline fishery. Endanger Species Res 5:267-278.

Jiménez S, Domingo A, Brazeiro A (2009) Seabird bycatch in the Southwest Atlantic: Interaction with the Uruguayan pelagic longline fishery. Polar Biol 32:187-196.

Kranstauber B, Safi K, Bartumeus F (2014) Bivariate Gaussian bridges: Directional factorization of diffusion in Brownian bridge models. Mov Ecol 2:5.

Lewison RL, Crowder LB (2003) Estimating fishery bycatch and effects on a vulnerable seabird population. Ecol Appl 13:743-753.

Løkkeborg S (2003) Review and evaluation of three mitigation measures-bird-scaring line, underwater setting and line shooter - to reduce seabird bycatch in the north Atlantic longline fishery. Fish Res 60:11-16.

Ministry for Primary Industries (2014) Aquatic Environment and Biodiversity Annual Review 2014. Compiled by the Fisheries Management Science Team, Ministry for Primary Industries, Wellington, New Zealand

Moore PJ (2004) Abundance and population trends of mollymawks on Campbell Island. Department of Conservation

Murray TE, Bartle JA, Kalish SR, Taylor PR (1993) Incidental capture of seabirds by Japanese Southern Bluefin Tuna longline vessels in New Zealand waters, 1988-1992. Bird Conserv Int 3:181-210. 
Nel DC, Ryan PG, Watkins BP (2002) Seabird mortality in the Patagonian toothfish longline fishery around the Prince Edward Islands, 1996-2000. Antarct Sci 14:151-161. doi: $10.1017 /$ S0954102002000718

Patrick SC, Bearhop S, Bodey TW, et al (2015) Individual seabirds show consistent foraging strategies in response to predictable fisheries discards.

Phillips RA, Silk JR, Croxall JP, Afanasyev V (2006) Year-round distribution of Whitechinned Petrels from South Georgia: Relationships with oceanography and fisheries. Biol Conserv 129:336-347.

Pierre JP, Abraham ER, Middleton DA, et al (2010) Reducing interactions between seabirds and trawl fisheries: Responses to foraging patches provided by fish waste batches. Biol Conserv 143:2779-2788.

Robertson CJR, Nunn GB (1998) Towards a new taxonomy for albatrosses. Albatross Biol Conserv Surrey Beatty Sons Chipping Nort Aust 23:13-19.

Rolland V, Weimerskirch H, Barbraud C (2010) Relative influence of fisheries and climate on the demography of four albatross species. Glob Change Biol 16:1910-1922. doi: 10.1111/j.1365-2486.2009.02070.x

Sagar PM (2014) Population estimates and trends of Campbell and Grey-headed Albatrosses at Campbell Island. NIWA

Sangster G, Collinson JM, Crochet P-A, et al (2013) Taxonomic recommendations for Western Palearctic birds: ninth report. Ibis 155:898-907.

Sullivan BJ, Reid TA, Bugoni L (2006) Seabird mortality on factory trawlers in the Falkland Islands and beyond. Biol Conserv 131:495-504.

Sztukowski LA (2016) Foraging ecology of the Campbell Albatross: Individual specialisation and fisheries interactions. Plymouth University

Torres L, Thompson D, Bearhop S, et al (2011) White-capped Albatrosses alter fine-scale foraging behavior patterns when associated with fishing vessels. Mar Ecol Prog Ser 428:289-301. doi: 10.3354/meps09068

Torres LG, Sagar PM, Thompson DR, Phillips RA (2013a) Scaling down the analysis of seabird-fishery interactions. Mar Ecol Prog Ser 473:275-289.

Torres LG, Sagar PM, Thompson DR, Phillips RA (2013b) Scale-dependence of seabirdfishery data analysis and management: Reply to Croxall et al.(2013). Mar Ecol Prog Ser 493:301-304.

Tuck GN, Thomson RB, Barbraud C, et al (2015) An integrated assessment model of seabird population dynamics: Can individual heterogeneity in susceptibility to fishing explain abundance trends in Crozet Wandering Albatross?

Votier SC, Bearhop S, Fyfe R, Furness RW (2008) Temporal and spatial variation in the diet of a marine top predator- links with commercial fisheries. Mar Ecol Prog Ser $367: 223-232$. 
Votier SC, Bearhop S, Witt MJ, et al (2010) Individual responses of seabirds to commercial fisheries revealed using GPS tracking, stable isotopes and vessel monitoring systems. J Appl Ecol 47:487-497.

Votier SC, Bicknell A, Cox SL, et al (2013) A bird's eye view of discard reforms: Bird-borne 490 cameras reveal seabird/fishery interactions. PloS One 8:e57376.

491

Waugh SM, Weimerskirch H, Moore PJ, Sagar PM (1999) Population dynamics of Blackbrowed and Grey-headed Albatrosses Diomedea melanophrys and D. chrysostoma at Campbell Island, New Zealand, 1942-96. Ibis 141:216-225.

494 
Table 1. The effects of sex, breeding stage, and year on the minimum distance between Campbell Albatross and fishing vessels using linear mixed-effects models. Models included individual bird as a random effect (to control for repeat samples from the same bird).

\begin{tabular}{|c|c|c|c|}
\hline \multicolumn{4}{|c|}{$\begin{array}{l}\text { Distance Between Albatross and Fishing } \\
\text { Vessels (Full Dataset) }\end{array}$} \\
\hline & DF & F-value & $\mathrm{p}$-value \\
\hline Intercept & 17659 & 3882.03 & \\
\hline Sex & 79 & 0.16 & $\begin{array}{c}0.69 \\
<0.000\end{array}$ \\
\hline Stage & 17659 & 572.41 & 1 \\
\hline Year & 17659 & 6.57 & 0.01 \\
\hline Sex*Stage & 17659 & 2.28 & 0.13 \\
\hline
\end{tabular}

Distance Between Albatross and Fishing Vessels (Within 2 hours and $\leq 11 \mathrm{~km}$ )

\begin{tabular}{lccc} 
& DF & F-value & p-value \\
\hline Intercept & 21 & 23.94 & \\
Sex & 12 & 0.38 & 0.55 \\
& & & \\
Stage & 21 & 0.019 & 0.92 \\
Year & 12 & 4.73 & 0.05 \\
\hline
\end{tabular}

\begin{tabular}{lrrr}
\hline \multicolumn{4}{l}{ Distance Between Albatross and Fishing } \\
\multicolumn{4}{c}{ Vessels (Within 2 hours and $\leq 30 \mathrm{~km}$ ) } \\
& DF & F-value & p-value \\
\hline Intercept & 55 & 59.39 & \\
Sex & 18 & 1.70 & 0.21 \\
Stage & 55 & 1.04 & 0.31 \\
Year & 18 & 0 & 0.98
\end{tabular}


Table 2. Interaction characteristics of foraging trips within $11 \mathrm{~km}$ or $30 \mathrm{~km}$ and 2 hours of fishing vessel location.

\begin{tabular}{|c|c|c|c|c|c|c|c|c|c|c|}
\hline \multirow[b]{2}{*}{ Individual } & \multirow[b]{2}{*}{$\begin{array}{c}\text { Foraging } \\
\text { Trip }\end{array}$} & \multirow[b]{2}{*}{ Sex } & \multirow[b]{2}{*}{ Stage } & \multirow[b]{2}{*}{ Year } & \multicolumn{3}{|c|}{ Within $11 \mathrm{~km}$ and 2 hours } & \multicolumn{3}{|c|}{ Within $30 \mathrm{~km}$ and 2 hours } \\
\hline & & & & & $\begin{array}{c}\text { Number } \\
\text { of } \\
\text { Vessels }\end{array}$ & $\begin{array}{c}\text { Number } \\
\text { of } \\
\text { Locations }\end{array}$ & $\begin{array}{c}\text { Proportion } \\
\text { of Trip }\end{array}$ & $\begin{array}{c}\text { Number } \\
\text { of } \\
\text { Vessels }\end{array}$ & $\begin{array}{c}\text { Number } \\
\text { of } \\
\text { Locations }\end{array}$ & $\begin{array}{c}\text { Proportion } \\
\text { of Trip }\end{array}$ \\
\hline 1 & 1 & Female & Incubation & 2011 & 0 & 0 & 0 & 1 & 7 & 0.00 \\
\hline 2 & 2 & Female & Incubation & 2012 & 0 & 0 & 0 & 4 & 8 & 0.00 \\
\hline 3 & 3 & Female & Incubation & 2012 & 8 & 103 & 0.04 & 11 & 232 & 0.09 \\
\hline 3 & 4 & Female & Incubation & 2012 & 6 & 246 & 0.14 & 6 & 506 & 0.30 \\
\hline 3 & 5 & Female & Chick Brooding & 2012 & 0 & 0 & 0 & 3 & 6 & 0.02 \\
\hline 4 & 6 & Female & Incubation & 2012 & 0 & 0 & 0 & 3 & 32 & 0.02 \\
\hline 4 & 7 & Female & Incubation & 2012 & 1 & 7 & 0.01 & 1 & 18 & 0.02 \\
\hline 5 & 8 & Female & Incubation & 2012 & 1 & 3 & 0.00 & 7 & 46 & 0.03 \\
\hline 6 & 9 & Female & Incubation & 2012 & 1 & 2 & 0.00 & 1 & 30 & 0.01 \\
\hline 7 & 10 & Male & Chick Brooding & 2011 & 1 & 2 & 0.00 & 1 & 11 & 0.01 \\
\hline 8 & 11 & Male & Incubation & 2012 & 0 & 0 & 0.00 & 4 & 28 & 0.01 \\
\hline 9 & 12 & Male & Incubation & 2012 & 6 & 962 & 0.49 & 7 & 1274 & 0.65 \\
\hline 10 & 13 & Male & Incubation & 2012 & 1 & 5 & 0.01 & 1 & 53 & 0.10 \\
\hline 10 & 14 & Male & Chick Brooding & 2012 & 2 & 17 & 0.05 & 3 & 71 & 0.20 \\
\hline 11 & 15 & Male & Incubation & 2012 & 1 & 11 & 0.01 & 1 & 20 & 0.01 \\
\hline 12 & 16 & Male & Incubation & 2012 & 1 & 21 & 0.01 & 5 & 50 & 0.02 \\
\hline 13 & 17 & Male & Chick Brooding & 2012 & 1 & 39 & 0.14 & 1 & 65 & 0.23 \\
\hline 14 & 18 & Male & Incubation & 2012 & 1 & 15 & 0.01 & 2 & 32 & 0.01 \\
\hline 15 & 19 & Male & Incubation & 2012 & 1 & 53 & 0.02 & 3 & 122 & 0.04 \\
\hline 16 & 20 & Male & Incubation & 2012 & 1 & 1 & 0.00 & 1 & 12 & 0.00 \\
\hline 17 & 21 & Male & Incubation & 2012 & 0 & 0 & 0 & 2 & 22 & 0.01 \\
\hline 18 & 22 & Male & Incubation & 2012 & 0 & 0 & 0 & 1 & 5 & 0.00 \\
\hline 19 & 23 & Male & Chick Brooding & 2012 & 0 & 0 & 0 & 1 & 16 & 0.04 \\
\hline
\end{tabular}


Incubation 2012

2012
2012

Male Incubation 2012

23

0.02

6

107

0.07

$3 \quad 0.00$

12

0.00 

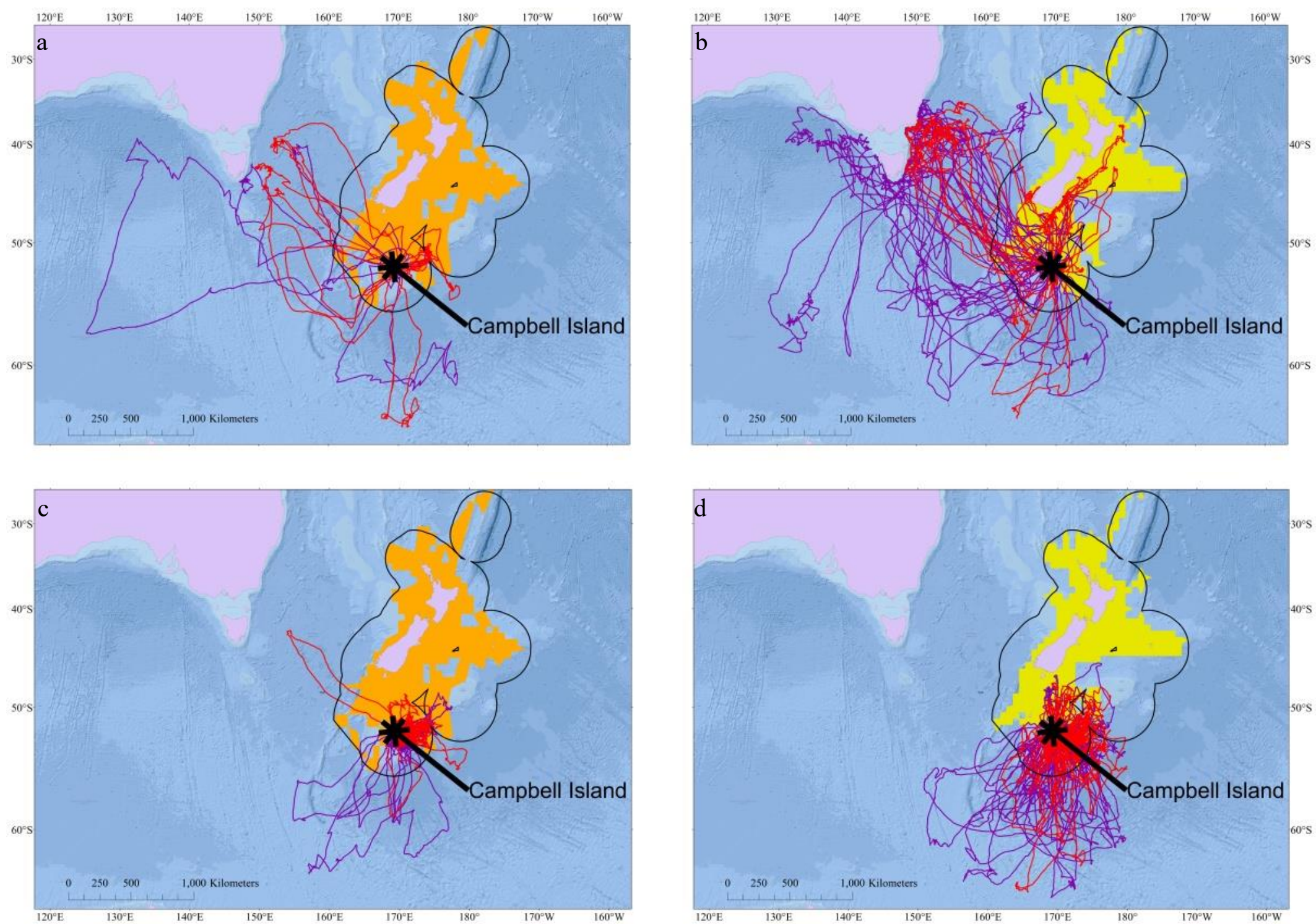
Fig. 1. Spatial overlap between fishing vessels (2011: orange, 2012: yellow) and foraging trips within New Zealand's Exclusive Economic Zone (black) during: a) incubation in $2011(\mathrm{n}=18)$, b) incubation in $2012(\mathrm{n}=41)$, c) chick brooding during 2011 ( $\mathrm{n}=79)$ and d) chick brooding during $2012(\mathrm{n}=161)$. Foraging trips were undertaken by females (red) and males (purple). Vessel monitoring data were transformed into a polygon. 
Supplemental material. Distance travelled and spatial utilization (area) per foraging trip (mean \pm standard deviation) for Campbell Albatrosses within New Zealand's Exclusive Economic Zone (EEZ). Data are sub-divided by sex and stage of reproduction (incubation or chick brooding).

\begin{tabular}{lclcccccc}
\hline Sex & Year & Stage & $\begin{array}{c}\text { Number } \\
\text { of Trips }\end{array}$ & $\begin{array}{c}\text { Number of } \\
\text { Individuals }\end{array}$ & Area $\left(\mathrm{km}^{2}\right)$ & $\begin{array}{c}\text { Distance } \\
\text { Travelled }(\mathrm{km})\end{array}$ & $\begin{array}{c}\text { Time Inside } \\
\text { EEZ (hours) }\end{array}$ & $\begin{array}{c}\text { Time Outside } \\
\text { EEZ (hours) }\end{array}$ \\
\hline Female & 2011 & Incubation & 12 & 11 & $2149.8 \pm 1222.7$ & $2482.3 \pm 1858.5$ & $23.4 \pm 33.5$ & $48.7 \pm 100.2$ \\
Female & 2012 & Incubation & 16 & 13 & $3048.7 \pm 2618.0$ & $3892.9 \pm 3013.3$ & $55.3 \pm 97.7$ & $152.0 \pm 168.2$ \\
Female & 2011 & Chick Brooding & 44 & 15 & $1172.7 \pm 737.2$ & $639.4 \pm 602.8$ & $35.1 \pm 19.1$ & $17.0 \pm 28.6$ \\
Female & 2012 & Chick Brooding & 80 & 27 & $1375.3 \pm 1088.3$ & $843.6 \pm 784.8$ & $23.2 \pm 18.5$ & $15.4 \pm 22.0$ \\
Male & 2011 & Incubation & 6 & 6 & $1570.7 \pm 870.4$ & $3552.8 \pm 3441.1$ & $25.3 \pm 20.3$ & $166.2 \pm 101.7$ \\
Male & 2012 & Incubation & 25 & 24 & $2466.5 \pm 1244.7$ & $5558.9 \pm 4159.6$ & $35.5 \pm 55.5$ & $217.9 \pm 165.4$ \\
Male & 2011 & Chick Brooding & 35 & 11 & $1112.6 \pm 656.5$ & $805.0 \pm 875.9$ & $35.8 \pm 31.9$ & $27.0 \pm 28.5$ \\
Male & 2012 & Chick Brooding & 81 & 27 & $1372.9 \pm 935.1$ & $1117.3 \pm 973.0$ & $20.5 \pm 16.3$ & $34.5 \pm 31.4$ \\
\hline
\end{tabular}

